\title{
Kinetika Adsorpsi Gas Benzena Pada Karbon Aktif Tempurung Kelapa
}

\author{
Rizky B. Hollea ${ }^{*}$, Audy D. Wuntua, Meiske S. Sangia \\ aJurusan Kimia, FMIPA, Unsrat, Manado
}

KA T A K U N C I

Kinetika adsorpsi

Benzena

Karbon aktif

Tempurung kelapa

\begin{tabular}{l}
\hline K E Y W O R D S \\
\hline Adsorption kinetics \\
Benzene \\
Activated carbon \\
Coconut shell
\end{tabular}

AVAILABLE ONLINE 20 Oktober 2013

\begin{abstract}
A B S T R A K
Telah diteliti kinetika adsorpsi gas benzena pada karbon aktif tempurung kelapa yang diaktivasi dengan $\mathrm{NaCl}$ dengan tujuan menentukan model kinetika yang dapat diaplikasikan untuk adsorpsi gas benzena pada karbon aktif tempurung kelapa. Data adsorpsi dianalisis dengan menggunakan empat model persamaan laju adsorpsi yaitu (1) persamaan laju order pertama pseudo Lagergren, (2) persamaan laju order kedua pseudo Ho, (3) persamaan Elovich, dan (4) persamaan Ritchie. Hasil kajian menunjukkan bahwa model kinetika dengan persamaan laju order ke-2 pseudo Ho adalah yang paling sesuai diaplikasikan untuk adsorpsi gas benzena pada karbon aktif tempurung kelapa. Dari model kinetika order ke-2 pseudo Ho diperoleh konstanta adsorpsi benzena sebesar $1,63 \times 10^{-4} \mathrm{~g} \mathrm{mg}^{-1} \mathrm{~min}^{-1}$. Nilai energi adsorpsi menunjukkan bahwa benzena teradsorpsi secara fisik pada adsorben. A B S T R A C T

Kinetics of gaseous benzene adsorption on coconut shell $\mathrm{NaCl}$ activated carbon had been studied. The research was aimed to determine the appropriate kinetic model applied to gaseous benzene adsorption on the adsorbent. Adsorption data was analyzed using four kinetic models of adsorption rate equation, which were (1) Lagergren's pseudo first order rate equation, (2) Ho's pseudo second order rate equation, (3) Elovich's equation, and (4) Ritchie's equation. The results showed that the Ho's pseudo second order rate equation was best applied to gaseous benzene adsorption on coconut shell activated carbon. The second order rate constant for benzene adsorption was $1.63 \times 10^{-4} \mathrm{~g} \mathrm{mg}^{-1} \mathrm{~min}^{-1}$. The value of adsorption energy showed that benzene was physically adsorbed on the adsorbent.
\end{abstract}

\section{Pendahuluan \\ Perkembangan industri dan teknologi manusia dalam beberapa dekade terakhir memberikan banyak manfaat dan kemudahan bagi manusia itu sendiri. Seiring dengan berbagai perkembangan tersebut, timbul masalah baru yakni terjadinya penurunan kualitas udara akibat adanya peningkatan pencemaran udara. Pencemaran udara dapat diakibatkan oleh asap yang dihasilkan dari sumber-sumber industri atau pabrik, kendaraan bermotor dan pembakaran.}

Menurut berbagai studi kasus yang telah dilakukan asap yang dikeluarkan oleh kendaraan bermotor sebagian besar terdiri dari oksida nitrogen, sulfur dioksida, karbon monoksida, dan karbon dioksida (Astra, 2010). Selain zat-zat di atas benzena merupakan hidrokarbon minyak bumi yang paling banyak menyebabkan pencemaran udara (Nourmoradi et al., 2013). Benzena diketahui teremisi pada pembakaran batu bara, minyak bumi, gas alam, gas pada pembangkit tenaga listrik, mesin kendaraan, tungku pembakaran bahkan perapian (Astra, 2010).

Adsorpsi adalah salah satu alternatif untuk mengatasi pencemaran udara. Langkah awal untuk mendapatkan proses adsorpsi yang efektif adalah dengan cara memilih adsorben yang memiliki

*Corresponding author: Jurusan Kimia FMIPA UNSRAT, Jl. Kampus Unsrat, Manado, Indonesia 95115; Email address: dribas@rocketmail.com 
selektivitas dan kapasitas tinggi serta dapat digunakan berulang ulang. Salah satu adsorben yang sering digunakan adalah karbon aktif.

Di Indonesia kelapa merupakan salah satu tumbuhan yang sudah lama dikenal dan terdapat di seluruh wilayah Indonesia. Bagian kelapa yang sering digunakan sebagai bahan dasar karbon aktif adalah tempurung kelapa. Karbon aktif adalah karbon yang konfigurasi atom karbonnya dibebaskan dari ikatan dengan unsur lain, serta pori dibersihkan dari senyawa lain sehingga permukaan dan pusat aktif menjadi luas dan daya adsorpsi terhadap cairan atau gas akan meningkat. Karbon aktif merupakan adsorben yang baik untuk pemurnian, menghilangkan warna dan bau, deklorinasi, detoksifikasi, penyaringan, pemisahan, dan dapat digunakan sebagai katalis (Bansal et al., 1988).

Studi adsorpsi gas pada karbon aktif telah banyak dilakukan, tetapi penelitian tersebut sebagian besar hanya mengkaji energi adsorpsi, aspek termodinamika serta aspek kesetimbangan. Aspek kinetika belum banyak diteliti, padahal dengan mengetahui aspek kinetika maka akan diketahui seberapa cepat proses adsorpsi tersebut berlangsung.

Kinetika adsorpsi merupakan salah satu aspek yang sering diteliti untuk mengevaluasi karakteristik dari adsorben yang dipakai terutama dalam rehabilitasi lingkungan. Ada banyak model kinetika adsorpsi yang telah dikembangkan untuk dapat digunakan sebagai sarana memprediksi laju adsorpsi suatu adsorbat pada adsorben tertentu. Beberapa model yang telah dikaji oleh Qiu et al., (2009) dan Ho (2004) yaitu (1) persamaan laju order pertama pseudo Lagergren, (2) persamaan laju order kedua pseudo Ho, (3) persamaan Elovich, dan (4) Persamaan Ritchie.

\section{Metode}

Penelitian ini dilakukan dalam dua tahap yaitu,

(1) Pembuatan karbon aktif tempurung kelapa, dan (2) penentuan waktu adsorpsi.

\subsection{Pembuatan Karbon Aktif Tempurung Kelapa}

Pembuatan karbon aktif tempurung kelapa dikerjakan mengikuti prosedur yang diuraikan oleh Bukasa et al. (2012) dengan modifikasi bahan mentah pembuatan arang dan bahan pengaktivasi. Tempurung kelapa dihaluskan hingga berbentuk glanular dengan diameter $\pm 2 \mathrm{~mm}$, kemudian dimasukkan ke dalam krus porselen dan dipanaskan dalam tanur dengan pemanasan $500^{\circ} \mathrm{C}$ selama 1,5 jam. Karbon yang dihasilkan kemudian direndam dengan larutan $\mathrm{NaCl} 10 \%$ selama 24 jam. Setelah direndam, karbon diaktivasi dengan pemanasan pada suhu $700{ }^{\circ} \mathrm{C}$ selama 2 jam dan dihasilkan karbon aktif. Karbon aktif yang diperoleh selanjutnya dicuci dengan akuades hingga mencapai $\mathrm{pH}$ netral. Selanjutnya karbon aktif dikeringkan dalam oven selama 3 jam pada suhu $110^{\circ} \mathrm{C}$.

\subsection{Penentuan Waktu Adsorpsi Pada Karbon Aktif Tempurung Kelapa}

Untuk menentukan waktu yang dibutuhkan dalam mencapai kesetimbangan adsorpsi benzena pada karbon aktif tempurung kelapa, disiapkan 8 buah alat eksperimen, masing-masing diisi dengan 10 g sampel arang aktif tempurung kelapa yang telah diketahui beratnya, kemudian dalam tiap alat dimasukkan benzena sebanyak $0,5 \mathrm{~mL}$. setelah wadah ditutup, alat dijalankan selama 1, 2, 3, 4, 5, 10, 18, 24 jam. Waktu setimbang dapat diketahui dengan membuat grafik antara banyak toluena yang teradsorpsi dibagi massa adsorben dengan variasi waktu tersebut. Data yang diperoleh kemudian dianalisis menggunakan persamaan laju order pertama pseudo Lagergren, persamaan laju order kedua pseudo Ho, persamaan Elovich dan persamaan Ritchie.

\section{(a) Persamaan Laju Order Pertama Pseudo Lagergren.}

Bentuk persamaan laju order pertama pseudo Lagergren adalah:

$$
\log \left(q_{e}-q_{t}\right)=\operatorname{loq} q_{e}-\left(\frac{k}{2.303}\right) t
$$

di mana $\mathrm{q}_{\mathrm{e}}$ adalah kapasitas adsorpsi pada saat kesetimbangan, qt adalah kapasitas adsorpsi pada waktu $\mathrm{t}$, dan $\mathrm{k}$ adalah konstanta laju order pertama pseudo. Plot dari $\log \left(q_{e}-q_{t}\right)$ vs. waktu (t) akan memberikan garis lurus dan koefisien determinasi $\mathrm{R}^{2}$ dapat ditentukan.

(b) Persamaan Laju Order Kedua Pseudo Ho. Persamaan ini dinyatakan dalam bentuk:

$$
\frac{t}{q_{t}}=\frac{1}{V_{0}}+\frac{1}{q_{e}} t
$$

di mana $V_{0}$ adalah laju adsorpsi awal yang setara dengan konstanta laju order kedua pseudo dikalikan dengan $\mathrm{q}^{2}$ dan $\mathrm{q}_{\mathrm{e}}$ adalah jumlah adsorbat teradsorpsi pada waktu $\mathrm{t}$. Plot $t / q_{\mathrm{t}}$ vs. $\mathrm{t}$ akan menghasilkan garis lurus dan koefisien determinasi $\mathrm{R}^{2}$ dapat ditentukan.

\section{(c) Persamaan Elovich.}

Persamaan Elovich secara luas digunakan untuk menjelaskan adsorpsi partikel gas ke padat dan mempunyai persamaan:

$$
q=\alpha \ln (a \alpha)+\alpha \ln t
$$

di mana $q$ adalah jumlah gas yang teradsorpsi pada waktu $t, \alpha$ adalah konstan desorpsi, dan a adalah laju adsorpsi awal. Garis lurus dan $\mathrm{R}^{2}$ yang sesuai diperoleh dari plot $q$ vs. In $t$.

\section{(d) Persamaan Ritchie.}

Persamaan Ritchie juga secara luas digunakan untuk menjelaskan adsorpsi partikel gas ke padat dan mempunyai persamaan:

$$
\frac{q_{\infty}}{q_{\infty}-q}=\alpha t+1
$$


di mana $q$ dan $q_{\infty}$ berturut-turut adalah jumlah gas yang teradsorpsi pada waktu $t$ dan setelah waktu yang tak terbatas, dan $\alpha$ adalah konstanta laju. Plot dari $q_{\infty} /\left(q_{\infty}-q\right)$ vs. $t$ menghasilkan sebuah garis lurus.

\section{Hasil dan Pembahasan}

\subsection{Kinetika Adsorpsi}

Jumlah benzena yang teradsorpsi $\left(q_{t}\right)$ selama periode waktu (t) 1, 2, 3, 4, 5, 10, 18, dan 24 jam pada adsorben karbon aktif tempurung kelapa ditunjukkan pada Gambar 1 dan 2.

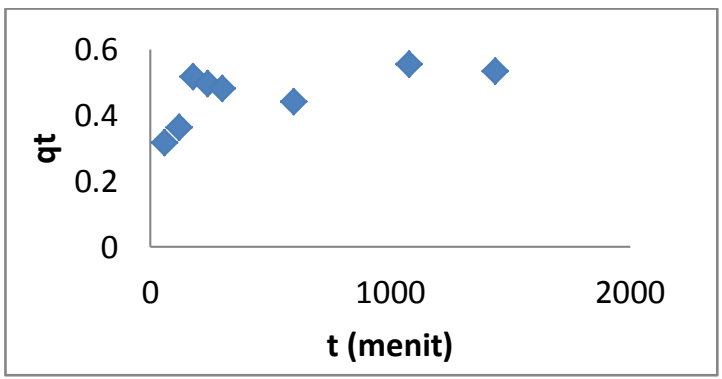

Gambar 1. Jumlah benzena teradsorpi $\left(q_{t}\right)$ selama waktu t pada karbon komersial

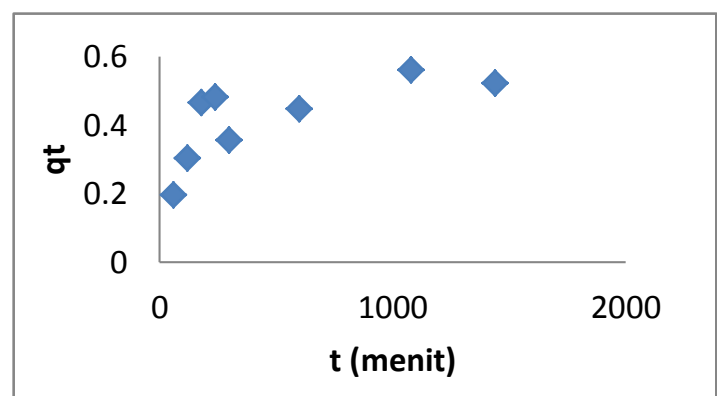

Gambar 2. Jumlah benzena teradsorpi $\left(q_{t}\right)$ selama waktu $\mathrm{t}$ pada karbon yang diaktivasi dengan $\mathrm{NaCl}$

Pada Gambar 1 dan 2 terlihat bahwa adsorpsi terjadi dengan cepat pada 4 sampai 5 jam pertama sebelum tercapai kesetimbangan yang ditunjukkan oleh kecilnya perubahan jumlah adsorbat yang teradsorpsi. Untuk mengetahui kinetika adsorpsi benzena pada karbon aktif komersial dan karbon aktif aktivasi $\mathrm{NaCl}$, data yang diperoleh dianalisis menggunakan empat model kinetika, yakni persamaan laju order pertama pseudo Lagergren, persamaan laju order kedua pseudo Ho, persamaan Elovich dan persamaan Ritchie.

Analisis regresi linear dari data adsorpsi gas benzena pada karbon aktif komersial dan karbon yang diaktivasi dengan $\mathrm{NaCl}$ menggunakan keempat model kinetika tersebut menunjukkan bahwa adsorpsi benzena pada karbon aktif yang diaktivasi dengan $\mathrm{NaCl}$ dan karbon aktif komersial mengikuti model kinetika order kedua pseudo Ho yang terlihat pada nilai koefisen determinasi $\mathrm{R}^{2}$. Nilai $\mathrm{R}^{2}$ berturutturut adalah 0.991 dan 0.985 untuk adsorpsi benzena pada karbon aktif komersil dan karbon yang diaktivasi $\mathrm{NaCl}$. Tabel 1 memperlihatkan nilai $\mathrm{R}^{2}$ untuk keempat model kinetika tersebut sedangkan Gambar 3 dan 4 memperlihatkan kurva regresi linear untuk model kinetika order kedua pseudo Ho.

Tabel 1. Nilai Koefisien Determinasi $\mathrm{R}^{2}$ untuk data adsorpsi benzena pada karbon aktif menurut model kinetika order pertama pseudo Lagergren, model kinetika order kedua pseudo Ho, Persamaan Elovich, dan Persamaan Ritchie

\begin{tabular}{|l|c|c|}
\hline Model kinetika & $\begin{array}{c}\text { Karbon } \\
\text { diaktivasi NaCl }\end{array}$ & $\begin{array}{c}\text { Karbon aktif } \\
\text { komersial }\end{array}$ \\
\hline $\begin{array}{l}\text { Model kinetika } \\
\text { order pertama } \\
\text { pseudo } \\
\text { Lagergren }\end{array}$ & 0.741 & 0.527 \\
\hline $\begin{array}{l}\text { Model kinetika } \\
\text { order kedua } \\
\text { pseudo Ho }\end{array}$ & 0,9857 & 0,9914 \\
\hline $\begin{array}{l}\text { Persamaan } \\
\text { Elovich }\end{array}$ & 0.651 & 0.621 \\
\hline $\begin{array}{l}\text { Persamaan } \\
\text { Ritchie }\end{array}$ & 0.489 & 0.537 \\
\hline
\end{tabular}

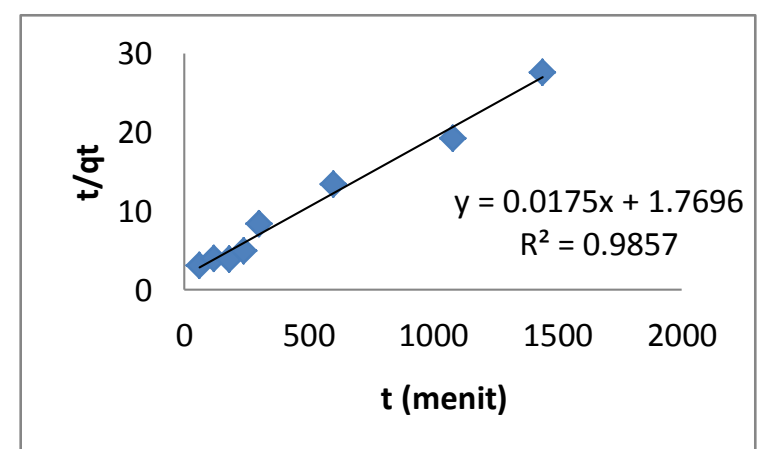

Gambar 3. Analisis model kinetika order kedua pseudo Ho untuk adsorpsi benzena pada karbon yang diaktivasi $\mathrm{NaCl}$

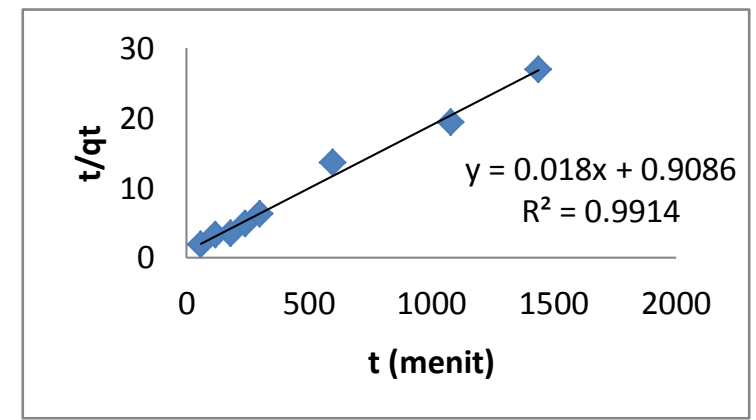

Gambar 4. Analisis model kinetika order kedua pseudo Ho untuk adsorpsi benzena pada karbon aktif komersil

Model kinetika order kedua pseudo Ho dikembangkan dari eksperimen adsorpsi logam pada gambut. Model ini didasarkan pada asumsi 
bahwa ion-ion logam divalen teradsorpsi secara kimia melalui penggunaan bersama atau pertukaraan elektron senyawa ion logam dan gambut. Meskipun demikian, model kinetika ini dapat juga diaplikasikan untuk adsorpsi gas pada padatan, misalnya adsorpsi $\mathrm{CO}_{2}$ (Rashidi et al., 2013) dan toluena (Wuntu dan Kamu, 2013) pada karbon aktif. Data dari penelitian ini juga menunjukkan bahwa model kinetika order kedua pseudo Ho ini juga dapat diaplikasikan untuk adsorpsi benzena pada karbon aktif. Parameterparameter dalam model kinetika order kedua pseudo Ho untuk adsorpsi benzena pada karbon aktif ditunjukkan pada Tabel 2 .

Tabel 2. Parameter pada model kinetika pseudo order kedua Ho untuk adsorpsi benzena pada karbon aktif

\begin{tabular}{|c|c|c|c|}
\hline & $\mathrm{qe}_{\mathrm{e}}\left(\mathrm{mg} \mathrm{g}^{-1}\right)$ & $\mathrm{k}\left(\mathrm{g} \mathrm{mg}^{-1} \mathrm{~min}^{-1}\right)$ & $\mathrm{V}_{\mathbf{0}}\left(\mathrm{mg} \mathrm{g}^{-1} \mathrm{menit}^{-1}\right)$ \\
\hline Karbon diaktivasi NaCl & 58.8235 & $1,63 \times 10^{-4}$ & 0.5652 \\
\hline Karbon aktif komersial & 55.5555 & $3,57 \times 10^{-4}$ & 1.1013 \\
\hline
\end{tabular}

$q_{e}=$ jumlah benzena teradsorpsi pada kesetimbangan

$\mathrm{K}=$ konstanta laju order kedua pseudo $\mathrm{Ho}$

$\mathrm{V}_{0}=$ laju awal

Pada Tabel 2 dapat dilihat bahwa konstanta laju adsorpsi (k) benzena pada karbon aktif komersial mempunyai nilai yang lebih besar dibandingkan konstanta laju adsorpsi (k) benzena pada karbon aktif yang diaktivasi dengan $\mathrm{NaCl}$. Ini menunjukkan bahwa adsorpsi benzena berlangsung lebih cepat pada karbon aktif komersial dibandingkan dengan adsorpsi pada karbon yang diaktivasi $\mathrm{NaCl}$. Laju adsorpsi yang lebih besar dapat dilihat juga pada nilai laju adsorpsi awal $\left(\mathrm{V}_{0}\right)$.

\subsection{Mekanisme Adsorpsi}

Mekanisme adsorpsi dapat dijelaskan dengan menggunakan model difusi intra partikel. Proses adsorpsi terdiri dari beberapa tahap diantaranya pergerakan partikel dari luar adsorben ke permukaan adsorben dan kemudian diikuti oleh difusi molekul ke dalam pori. Difusi intra partikel umumnya merupakan proses yang lambat dan dianggap sebagai tahap penentu laju dalam proses adsorpsi. Adsorpsi intra partikel dinyatakan dengan persamaan Weber dan Morris (Ho et al., 2000).

$$
\mathrm{q}_{\mathrm{t}}=\mathrm{k}_{\mathrm{d}} \mathrm{t}^{1 / 2}
$$

di mana $q_{t}$ adalah jumlah adsorbat yang teradsorpsi pada waktu kontak $t$ dan $k_{d}$ adalah konstanta laju. Plot qt vs. $t^{1 / 2}$ seharusnya menghasilkan garis lurus jika proses adsorpsi mengikuti model difusi intra partikel. Gambar 5 dan 6 menunjukan plot $\mathrm{q}_{\mathrm{t}} \mathrm{vs}$. $\mathrm{t}^{1 / 2}$ untuk adsorpsi benzena pada karbon aktif.

Gambar 5 dan 6 menunjukkan adanya variasi gradien dan hal ini menunjukkan bahwa difusi intra partikel bukan satu-satunya tahap penentu laju dalam proses adsorpsi ini. Kurva dengan gradien yang lebih besar menggambarkan proses adsorpsi yang berlangsung lebih cepat. Proses ini terjadi pada awal proses adsorpsi dan kemungkinan menggambarkan proses adsorpsi yang di kontrol oleh pergerakan molekul ke permukaan padatan adsorben. Kurva dengan gradien lebih kecil menggambarkan proses yang berlangsung lebih lambat. Tahap ini terjadi setelah tahap pertama dan kemungkinan merupakan proses adsorpsi yang di kontrol oleh difusi intra partikel.

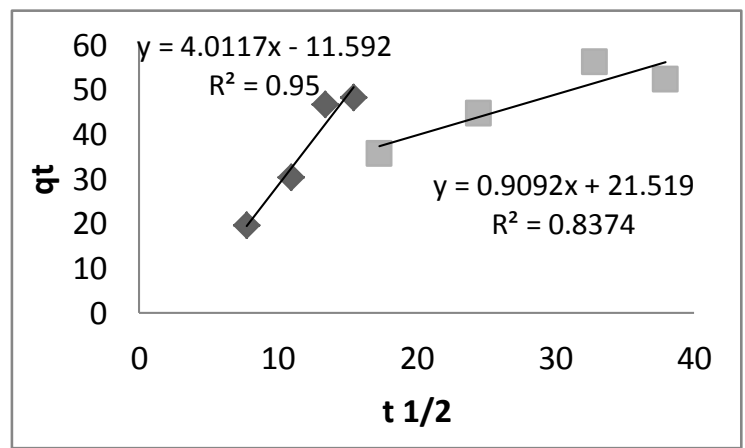

Gambar 5. Plot $\mathrm{q}_{\mathrm{t}}$ vs. $\mathrm{t}^{1 / 2}$ untuk adsorpsi benzena pada karbon yang diaktivasi $\mathrm{NaCl}$

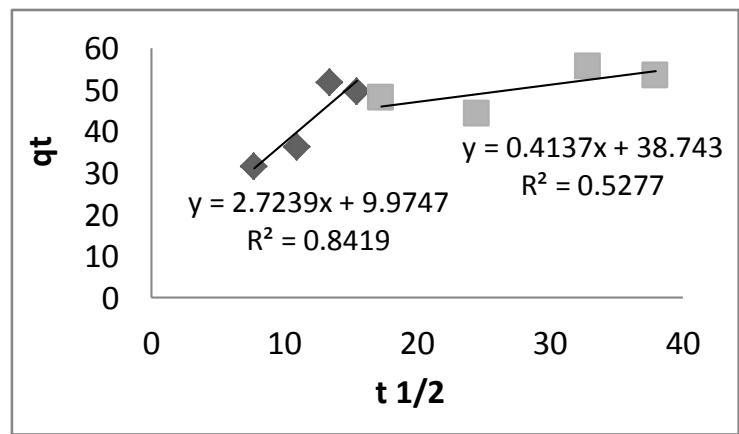

Gambar 6. Plot $\mathrm{q}_{\mathrm{t}}$ vs. $\mathrm{t}^{1 / 2}$ untuk adsorpsi benzena pada karbon aktif komersial

\subsection{Energi Adsorpsi}

Energi adsorpsi menggambarkan kekuatan ikatan antara adsorbat dan adsorben. Energi adsorpsi dibedakan atas dua yakni adsorpsi fisik dan adsorpsi kimia. Adsorpsi fisik terjadi jika reaksi antara adsorben dan adsorbat melibatkan gayagaya lemah antar molekul seperti ikatan hidrogen atau ikatan van der Waals. Pada proses ini molekul yang teradsorpsi mudah di lepas kembali dengan menurunkan tekanan gas atau konsentrasi zat 
terlarut. Zat yang teradsorpsi dapat membentuk lapisan tunggal dan kondisi kesetimbangan akan tercapai segera setelah adsorben bersentuhan dengan adsorban (Suseno, 2011).

Pada adsorpsi kimia terjadi pembentukan ikatan kimia antara molekul adsorbat dengan permukaan adsorben (Kundari dan Slamet, 2008). Adsorpsi kimia melibatkan ikatan koordinasi sebagai hasil penggunaan bersama pasangan elektron oleh adsorbat dan adsorben (Rahmawati dan Santoso, 2012). Umumnya adsorpsi fisika memiliki nilai energi lebih kecil dari 25-30 $\mathrm{kJ} \mathrm{mol}^{-1}$ (Ho et al., 2000). Nilai energi adsorpsi dapat dihitung dari persamaan Arrhenius

\section{$E=-R T \ln k$}

$\mathrm{k}=$ konstanta laju orde kedua pseudo Ho.

$\mathrm{E}=\operatorname{energi}\left(\mathrm{J} \mathrm{mol}^{-1}\right)$

$\mathrm{R}=$ konstanta gas $\left(8,314 \mathrm{~J} \mathrm{~K}^{-1} \mathrm{~mol}^{-1}\right)$

$\mathrm{T}=$ suhu mutlak $(\mathrm{K})$

Dengan menggunaan persamaan tersebut dapat ditentukan nilai energi adsorpsi yang ditunjukkan pada Tabel 3

Tabel 3. Nilai Koefisien Determinasi $\mathrm{R}^{2}$ untuk data adsorpsi benzena pada karbon aktif menurut model kinetika order pertama

\begin{tabular}{|c|c|}
\hline \multicolumn{1}{|c|}{ Adsorben } & $\begin{array}{c}\text { Energi adsorpsi } \\
\left(\mathrm{J} \mathrm{mol}^{-1}\right)\end{array}$ \\
\hline Karbon diaktivasi $\mathrm{NaCl}$ & 21603.18 \\
\hline Karbon aktif komersial & 19667.6 \\
\hline
\end{tabular}

Tabel 3 menunjukkan bahwa adsorpsi yang terjadi antara karbon aktif baik karbon yang diaktivasi dengan $\mathrm{NaCl}$ dan karbon aktif komersial menunjukkan bahwa adsorpsi benzena pada karbon aktif merupakan adsorpsi fisika. Pada adsorpsi ini tidak terjadi pertukaran elektron atau penggunaan bersama elektron. Adsorpsi fisika antara benzena dan karbon aktif diduga melibatkan gaya Van der Waals berupa interaksi dipol-dipol dan dipol terinduksi.

\section{Kesimpulan}

Dari penelitian yang dilakukan dapat disimpulkan bahwa kinetika adsorpsi gas benzena pada karbon aktif tempurung kelapa yang diaktivasi dengan $\mathrm{NaCl}$ dan karbon aktif komersial lebih mengikuti persamaan order kedua pseudo Ho dan adsorbat teradsorpsi secara fisik pada adsorben. Mekanisme adsorpsi ini melalui dua tahap yaitu pergerakan molekul adsorbat ke permukaan partikel adsorben kemudian diikuti oleh difusi intra partikel dimana adsorbat bergerak dari permukaan partikel ke dalam pori adsorben. Tahap pertama berlangsung cepat sedangkan tahap yang kedua berlangsung lebih lambat.

\section{Daftar Pustaka}

Astra, I M. 2010. Energi dan Dampaknya Terhadap Lingkungan. Jurnal Meterologi dan Geofisika. 11: $127-135$.

Bukasa, D. A., H. S. J. Koleangan., A. D. Wuntu. 2012. Adsorpsi Toluena Pada Arang Aktif Tempurung Kemiri. Jurnal IImiah Sains. 12: 93 99.

Bansal, C. R., J. B Donnet, F. Stoekli. 1988. Active Carbon. Marcel Dekker Inc., New York.

Ho, Y. S., J. C. Y. Ng., G. McKay. 2000. Kinetics of Pollutant Sorption by Biosorbent : Review. Separation And Purification Methods. 29: 189 232.

Ho, Y. S. 2004. Cititation Review of Lagergren Kinetic Rate Equation on Adsorpstion Reactions. Scientometrics. 59: 171 - 177.

Kundari, N. A., W. Slamet. 2008. Tinjauan Kesetimbangan Adsorpsi Tembaga Dalam Limbah Pencuci PCB dengan Zeolit. Seminar Nasional IV SDM Teknologi Nuklir Yogyakarta, 25-26 Agustus [Prosiding].

Nourmoradi, H., M. Khiadani., M, Nikaeen. 2013. Multi-Component Adsorption of Benzene, Touene, Ethylbenzene, and Xylene from Aqueous Sulutions by Montmorillonite Modified with Tetradecyl Trimethyl Ammonium Bromide. Journal of Chemistry. $2013: 1$ - 10

Rahmawatia A., S. J. Santoso. 2012. Studi Adsorpsi Logam $\mathrm{Pb}$ (li) Dan Cd(li) Pada Asam Humat Dalam Medium Air. Alchemy. 2 : 46 - 57.

Rashidi, N. A., S. Yusup, L. H. Loong. 2013. Kinetic Studies on Carbon Dioxide Capture using Activated Carbon. Chemical Engineering Transactions. $35: 361$ - 366.

Qiu, H., Bing, C, P., Qing-jing, Z., Wei-ming, Z.,Quangxing, Zhang. 2009. Critical Review in Adsorption Kinetick Model. Journal of Zhejiang University SCIENCE A. 10: 716 - 724.

Suseno, H. P. 2011. Model Adsorpsi $\mathrm{Mn}^{+2}, \mathrm{Cd}^{+2}$ Dan $\mathrm{Hg}^{+2}$ Dalam Sistem Air-Sedimen Sepanjang Sungai Code, Yogyakarta. Jurnal Teknologi, 4: 174 - 179.

Wuntu, A. D., V. Kamu. 2013. Kinetics of Gaseous Toluene Adsorption on Dandlenut Shell Activated Carbon. Jurnal IImiah Sains. 13: 33 - 37. 